\title{
Kings and Vikings: on the dynamics of competitive agglomeration
}

\author{
Matthew J. Baker • Erwin H. Bulte
}

Received: 20 January 2009 / Accepted: 13 November 2009 / Published online: 17 December 2009

C) The Author(s) 2009. This article is published with open access at Springerlink.com

\begin{abstract}
This paper proposes a theory of competitive agglomeration-a new enquiry into the origins of hierarchical structures and governments. As a motivating example we analyze the Viking age-the roughly 300 year period beginning in $800 \mathrm{AD}$ - from the perspective of the economics of conflict. The Viking age is interesting because throughout the time period, the scale of conflict increased-small scale raiding behaviour eventually evolved into large scale clashes between armies. With this observation in mind, we present a theoretical model describing the incentives both the defending population and the invading population had to agglomerate into larger groups to better defend against attacks, and engage in attacks, respectively. We tentatively postulate that competitive agglomeration during the Viking era was a key impetus to state formation in Europe.
\end{abstract}

Keywords Conflict $\cdot$ European history $\cdot$ State formation

\section{JEL Classification $\quad \mathrm{D} 74 \cdot \mathrm{H} 56 \cdot \mathrm{N} 40 \cdot \mathrm{O} 12$}

"For what are thieves' purchases but little kingdoms, for in theft the hands of the underlings are directed by the commander, the confederacy of them is sworn together, and the pillage is shared by law amongst them? And if those ragamuffins grow up to be able to keep enough forts, build habitations, possess cities, and

\footnotetext{
M. J. Baker

Department of Economics, Hunter College, City University of New York, 695 Park Avenue, New York, NY 10021, USA

e-mail: Matthew.Baker@hunter.cuny.edu

E. H. Bulte $(\square)$

Development Economics Group, Wageningen University, P.O. Box 8130, 6700 EW Wageningen, The Netherlands

e-mail: erwin.bulte@wur.nl
} 
conquer adjoining nations, then their government is no more called thievish, but graced with the eminent name of a kingdom, given and gotten, not because they have left their practices, not because they have left their practices, but because they may now use them without danger of law."

—St. Augustine, City of God, iv.4., quoted in Sawyer (1994, p. x)

\section{Introduction}

Since the early 1990s, an important literature on the causes and intensity of conflict has emerged. Initiated by seminal work of Hirshleifer $(1991,1995)$ and Grossman (1991); see also Grossman and Kim (1995), several analysts have considered how rational agents allocate their endowments across productive and appropriative activities to maximize their payoffs. Since conflict, in various forms, has played a major role throughout human history — shaping the development trajectory of civilizationimproving our understanding of the nature of conflict appears extremely useful.

A slightly awkward feature of the conflict literature, until quite recently, was its focus on static modeling. While, arguably, there are examples where opponents contest a prize during one instant and return to their usual business (or similarly, examples where conflict may be approximated by a near 'steady state outcome' with ongoing and unchanging conflict), there are many other cases where a static approach is not appropriate. It is no surprise, therefore, that a number of recent papers, including Grossman and Mendoza (2003), Gonzalez (2005), and Mehlum and Moene (2006), explicitly incorporate dynamics by building in expectations about the future. ${ }^{1}$ But dynamics may also matter for different reasons, for example because the nature of conflict evolves over time. Conflicts may evolve because technologies and relative prices change due to some endogenous or exogenous process, or because the incentives to behave in a certain fashion are subject to change. In this paper we study how the scale of conflict changes over time, and discuss the incentives for agents to agglomerate into larger groups for the purposes of engaging in conflict. Agglomeration may enable parties to better defend themselves from aggressors, or to better exploit their weaker neighbors. The result is what can be called a theory of competitive agglomeration.

Our approach is motivated by the insight that dealing with issues of provision of defense and exploitation of neighbors was a primary reason for governments and larger political groups to form in the first place. Thus, our theory contributes to the literature on the origins and optimal size of political jurisdictions, providing an alternative explanation for the development of nation states (e.g. Alesina and Spolaore 1997, 2005a,b). Like other theories of state formation, scale economies are at the heart of our story, and optimal nation size is determined by balancing benefits and costs of increasing jurisdiction size. Unlike other theories, our theory of agglomeration stems from the nature of the conflict technology, and not from an assumption about fixed costs in the

\footnotetext{
1 Grossman and Mendoza (2003) consider the case where future survival depends on current success in conflict, Gonzalez (2005) analyses a model where the threat of future conflict (expropriation) affects the current decision to invest in technology, and Mehlum and Moene (2006) model the case of conflict in the presence of an incumbency edge (i.e., to be successful in conflict today implies an advantageous position tomorrow).
} 
provision of certain public goods. We show that the degree of agglomeration depends upon the technology by which defenders and invaders interact. Therefore, we provide a natural link between two strands of literature - analytical work on the size of nations (e.g. Friedman 1997; Bolton and Roland 1997; Alesina and Spolaore 1997) and on arms races (Schelling 1960; Sandler and Hartley 1995).

Our model focuses on the emergence of rulers and hierarchical structures, and combines elements of existing theories. Social contract theories argue that governments emerge whenever cooperation and coordination is socially optimal, or in the interest of "the people" (e.g. Buchanan 1975; Leeson 2006). ${ }^{2}$ Alternatively, predatory theories focus on predatory incentives and tradeoffs of the (potential) ruler. Olson (1993), Olson (2000) considers a set-up with many raiders and producers, and then explores when it is optimal for a roving bandit to settle down and become "king." Becoming the ruler essentially implies becoming a stationary bandit and acquiring monopoly powers to "tax" the people_- "rational theft" rather than "anarchic theft" is the outcome. ${ }^{3}$ Our approach fits in the social contract tradition in that we focus on incentives and tradeoffs for society, but uses predation (by outsiders) as the pivotal mechanism.

While the main objective of this paper is to contribute to a better understanding of the forces driving agglomeration in the face of conflict, we also wish to advance the conjecture that competitive conglomeration might have played an important role in state formation. For this purpose we shall discuss our theory in terms of a particularly dramatic example of predation: the era of the Viking invasions. The Viking invasions are an interesting and in many ways ideal historical episode within which to study agglomeration: only through effectively forming larger groups could European settlements deal with Viking raids, while at the same time Viking invasions evolved over time from small, disorganized attacks into large, organized invasions. Our theory also allows us to consider various hypotheses as to how the invasions got started in the first place (see Sect. 2 for details). In this paper we focus on these early days and on the development towards the peak of the Viking invasions. ${ }^{4}$

We believe the agglomeration patterns we study are not unique to that era. For example, in recent years similar agglomeration processes have possibly been at work in the Gulf of Aden, where piracy has been a threat to international shipping since the beginning of the civil war in the early 1990s. Initially, individual pirate boats attacked individual cargo vessels. In response to the losses they sustained, cargo ships started to coordinate their movements and started traveling in convoys. Also, a multinational coalition task force has established a Maritime Security Patrol Area, and individual countries started providing military escorts to vessels traveling the Gulf of Aden.

\footnotetext{
${ }^{2}$ In this tradition, Grossman (2002) focuses on the tradeoff that the people face when deciding to support a ruler, or not. A ruler solves society's coordination problems, but also subjects the people to taxes which will be used for the ruler's personal consumption.

3 Interestingly, McGuire and Olson (1996) demonstrate that, due to the "encompassing interest" of the stationary bandit in the state of the local economy, the ruler's policies do not deviate much from the policies chosen by a representative agent in the economy.

4 It bears mentioning that other episodes of barbarian invasion, such as the barbarian incursions into the Roman Empire and the Mongol invasions, also seemed to feature agglomeration of attackers into larger groups. However, the dynamics of the process in these cases are not well documented. For a brief description, see Craughwell (2008).
} 
Interestingly, the pirates' response to these defensive measures has been to engage in coordinated attacks. Hence rather than being discouraged and downscale their efforts, pirates now join forces and have even adopted the innovation of traveling on a "mother ship" carrying several pirate units. This allows joins attacks on convoys, and movements beyond the Gulf of Aden. Such dynamics are fully compatible with our model. ${ }^{5}$

Our model differs from much of the previous literature on the economics of conflict for a number of reasons. First and foremost, as mentioned above, we focus on agglomeration. Second, we explicitly consider the dynamics of this process. Others in the conflict literature (most notably perhaps, Skaperdas 1992 and Hirshleifer 1995) have considered "reaction functions" of players - an approach that is at least implicitly dynamic insofar that it allows analyzing the behavior of the system when it is out-of-equilibrium. But we extend this approach and trace an explicit expression for the system's dynamics by introducing a measure of friction or inertia. Time becomes a variable in the model and the system is amenable to conventional stability analysis and calibration exercises. ${ }^{6}$ Third, in our asymmetric model aggression can only flow one way-from a potential aggressor (the Vikings) to a potential victim (the British). This unidirectional focus implies middle ground between existing vertical models of conflict (e.g. insurrections and rebellion: the ruler versus the people-see for example Grossman 1991) and horizontal models of conflict (where tribes or agents compete for each other's output-e.g. Baker 2003), and also allows analyzing the decision of aggressors to participate in conflict. We discuss why unidirectional aggression, as opposed to symmetric violence or peace, may occur in Sect. 3. Finally, unlike most models of conflict our specification of the conflict process results in a model that is fully tractable. This applies both to a 'stripped down' version of the model as presented in the main text to illustrate the main story with as little distractions as possible, and to more elaborate specifications provided in separate appendices that serve as robustness analyses.

The paper is organized as follows. In Sect. 2 we provide a short history of the Vikings, fleshing out some of the more pertinent stylized facts. Section 3 introduces notation and sketches the bare bones of the basic model. In Sect. 4 we consider the relatively easy case where villages can 'agglomerate' into larger groups to improve their oomph in contests, but where the level of their contribution to the group is fixed. In Sect. 5 we allow villages to optimally choose their contribution (bearing in mind that investing in conflict effort comes at a cost). This allows us to trace out the full dynamic system, and analyze its properties. In section VI, we conjecture a link between agglomeration and state formation, proposing that the era of the Vikings was a decisive part of Europe's history. The section also concludes.

\footnotetext{
5 See Gettleman (2008a,b,c), Gettleman (2009), New York Times (2005), and Worth (2008).

6 The analysis is not fully dynamic in the sense that we do not start out with equations of motion to keep track of the evolution of some state variables. See Maxwell and Reuveny (2005) for an analysis in the conflict literature that follows this route. They develop a model where bands of myopic agents share access to a common pool. Both human fertility and resource dynamics are defined by differential equations, allowing a full analysis of the system's dynamics.
} 


\section{The viking invasions}

While our model can be applied to other interactions between populations of aggressors and defenders, the Viking age (roughly, the 300-year period beginning in c. 800 AD) is a convenient stage upon which to discuss the basic logic of our model. Like most historical epochs, pinning down an exact beginning and ending date for the Viking age is difficult, but historians agree that a good starting point is the raid on Lindesfarne, on the coast of Northumbria, on June 8th, 793. Shortly thereafter, Vikings turned up in a variety of places in the British Isles, and branched out to other coastal regions of Europe. ${ }^{7}$ A host of explanations have been proposed for why the Viking invasions began when they did (which we comment on below), including poor climate and deteriorating hunting and fishing conditions, growing internal strife, population pressure, increased commerce and prosperity in Northwestern Europe, advances in boat-building and sailing technology, and even boredom at home (Griffith 1995; Sawyer 1997).

Initial raids were directed primarily at coastal targets and conducted by relatively small fleets. Over time, Viking attacks evolved into bolder, better-organized and larger enterprises, so much so that by the mid ninth century, Viking armies were conducting organized, large-scale invasions. Sawyer (1994: 81) writes: "In the summer of 834, the great market of Dorestad, some $80 \mathrm{~km}$ from the sea, was attacked... and a new phase of Viking activity in Western Europe began." Large Viking forces appeared in Sheppey, on the Thames river, along the coast by Antwerp, in the interior of Ireland, and in the Bristol Channel; Dorestad was attacked again in 836. Viking fleets raided the Seine river basin in 841, and Hamburg in 845, led by the Danish King, Horik (Sawyer 1994). Viking forces attacked Nantes in 842, Seville in 844, Canterbury and London in 851, and even Pisa in 859 (Roberts 1993).

When the Vikings first attacked Lindesfarne, England was composed of a multitude of small kingdoms (Abels 1988b). However, a broad trend towards agglomeration into larger and better-organized units slowly took shape across Europe. Defense was mainly organized through royal or aristocratic levies, complemented by bottom-up efforts. On mainland Europe, for example, Louis the Pious, the Frankish king during the early part of the ninth century, took initial steps in organizing coastal defenses. Some years later (in 862), Charles put into motion a program of building bridges and fortresses at critical points along rivers.

These and other defensive efforts were not without success. Aethelstan (ruler of Kent), defeated the Vikings at sea (Kirby 1991), suggesting that the size, organization, and skill of defenders had kept pace with the size of the raiding parties. In turn, this development invited new and larger Viking armies arriving in England, which "seriously began to threaten the capabilities of the Anglo-Saxon kingdoms." (Kirby 1991: 172). The result was a process of agglomeration where both the English and the Vikings bunched up into larger units, culminating in the era of large-scale Viking invasions in the eleventh century - the final years of the Viking age. In the next section, we describe a simple formal model of this process. The cornerstone of the model is the idea that conflict involves some degree of scale economies.

\footnotetext{
7 These dates are drawn from Poertner (1971).
} 


\section{The model}

The agents in the model are divided into two separate populations: we shall call them Vikings and English. ${ }^{8}$ For some historical reason (unspecified in the model) we assume that the former might prey on the latter, but that the reverse cannot happen. ${ }^{9}$ Consider a population of $n$ distinct Viking villages, each of which makes a decision about whether to engage in raiding or to pursue a peaceable occupation, such as farming. Let the number of raiding villages be given by $n_{v}$ and the number of villages engaging in farming as $n_{f}$, so that $n=n_{v}+n_{f}{ }^{10}$

When engaging in raiding, Vikings randomly select an English target village. To successfully raid the target village, the raiders must overcome whatever defensive force the English target village has in place. We refer to the size of the defensive force as $D$. In conducting raids, Vikings may wish to combine forces with other, like-minded Viking villages. Agglomeration into a larger raiding group conveys an advantage - the massing of forces thus achieved admits a larger probability of raiding success. The downside is that a successful raiding group must split the returns thereby gained among its members.

Let $v$ denote the number of raiding villages participating in a given raiding group, and let $g$ denote the forces contributed by each village to the raiding group. Then, the size of the raiding force amassed is $G=g v$. In much of what follows, we shall assume that each group contributes all of its labor to raiding, which results in $G=v .^{11}$ Since all raiding groups are identical, it follows that across the population of villages engaging in raiding, the number of distinct raiding groups is $V=n_{v} / v$.

The likelihood a raid is successful is determined by a contest success function, which maps the relative size of the invading force and the size of the defensive force faced into a success probability. We assume that the contest success function is of the form:

$$
s(G, D)=\frac{G^{\rho}}{G^{\rho}+D^{\rho}} .
$$

The function (1) is standard, although it is worth emphasizing the role of the parameter $\rho$, which Hirshleifer (1995) refers to as a "decisiveness" parameter. We shall generally assume that $\rho>1$. When $\rho>1$, the contest success function is S-shaped, in force size, which implies that there are scale effects over some range of force sizes. The specification allows for increasing returns to force size to, for example, Vikings so long as $G \leq D$. Once the point $G=D$ is reached, diminishing returns to force size set in (see also Skaperdas 1992) As $\rho \rightarrow \infty$ the contest function approaches a step function

\footnotetext{
8 An interesting extension, which we do not entertain for reasons of brevity, would be to consider the interaction between a raiding population and two defending populations, e.g., the British and Franks.

9 Counterattacks did in fact occur, but were generally confined to attacks of Viking armies on English soil.

10 An alternative approach, which generates virtually identical results, is to allow all groups to contribute some positive fraction of their labor to raiding and some to farming.

11 This assumption, and generally, the assumption that raiding groups contribute a fixed amount to the raiding party is with little loss of generality. As detailed in the appendix, allowing for variable contributions from raiding groups to the joint effort does not substantially change our qualitative results.
} 
so that the slightly more powerful party wins the conflict with near certainty. This is a plausible approximation as far as we can infer from historical sources. ${ }^{12}$ Hirshleifer (1995) argues that this parameter is likely to be high when the nature of conflict favors the offensive side. This is because when $\rho$ is high, the defenders must operate on roughly the same scale as the intruders to have a chance of winning the conflict; if the defensive force is much smaller than the intruding force, they almost certainly will lose the conflict. Given that the Vikings often had the advantage of surprise, and could attack virtually anywhere they desired, it seems reasonable to suppose that the nature of conflict in the Viking era favored the invaders.

A successful raid results in winnings of amount $\pi .{ }^{13}$ Using $G=v$, the expected returns per village participating in the typical raiding group can be written as:

$$
x_{v}=\frac{r \pi}{v} \frac{v^{\rho}}{v^{\rho}+D^{\rho}} .
$$

In (2), $r$ denotes the number of raids the group becomes engaged in per period, which we take to be exogenous, perhaps determined by the state of shipping technology. ${ }^{14}$ Note that the first part of expression (2) includes the idea that expected winnings are divided by the number of villages in the raiding group. ${ }^{15}$ Success probabilities and payoffs for raiding groups as a function of group size/raiding effort (given defense level $d$ ) are depicted in Fig. 1. The inflection point (where the second derivative of the conflict function is 0$)$ occurs at $D[(\rho-1) /(\rho+1)]^{1 / \rho}$, while the maximum group returns occur at the point $D[(\rho-1)]^{1 / \rho}$. This means the inflection point is always to the left of the maximum return point - one wishes to be a bit larger than the opponent. The diagram also shows how the shape of these functions varies when $\rho$ takes on a value less than one. One can see from Fig. 1 that in these cases, returns per group are strictly decreasing in the size of the group; without some sort of scale effect in conflict, there is never a reason to form a larger raiding party.

\footnotetext{
12 Hirshleifer (2000) discusses conditions and historical episodes under which one might expect the decisiveness parameter to be relatively high (such as in Naval battles) or relatively low.

13 Since the contested prize, $\pi$, is treated as an exogenous parameter, the model is on the interface of conflict models and rent seeking models. As discussed by Neary (1997), most conflict models have a general equilibrium nature where agents contest the output they first produce themselves. However, since British villages cannot opt out of the game unilaterally, the model is of the conflict and not of the rent-seeking type. Also note that treating $\pi$ as a parameter implies ignoring the fact that the British will have to accumulate wealth after being raided, so that in reality $\pi\left(n_{v}, v, D\right)$. Such a model could, in theory, be solved for the length of the optimal raiding cycle, not unlike optimal cutting rotations in forestry (think of the traditional Faustmann model). However, such a model is intractable when we allow for endogenous agglomeration, and detracts a bit from the main point that we wish to get across.

14 In light of the evidence described in the previous section of the paper, it would seem important that a larger group should be able to conduct more raids. Allowing for this possibility makes things a bit messier, without fundamentally changing our results. We describe the impact of variable raids in the appendix.

15 Note that we do not formally include any transactions costs associated with group formation. This is done purely for simplicity, but transactions costs could be included by allowing some of the spoils to be lost in the process of distribution, and therefore replacing (2) with a specification like $x_{v}=\frac{r \pi}{v^{\gamma}} \frac{v^{\rho}}{v^{\rho}+D^{\rho}}$, with $\gamma>1$. In fact, transactions costs could be modeled explicitly using a conflict over resources between villages participating in the alliance, which generates much the same result. Game theoretic concerns in a game of this sort are discussed in Garfinkel and Skaperdas (2007).
} 


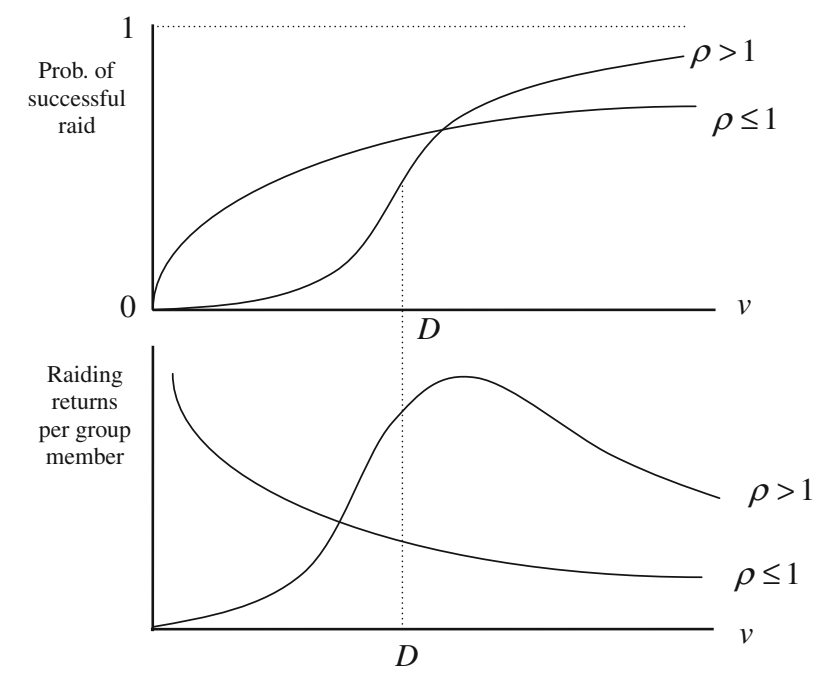

Fig. 1 Conflict technology and payoffs

We assume that optimal raiding group size is chosen to maximize the returns of the average member. ${ }^{16}$ Differentiating (2) with respect to $v$ gives the following:

$$
\frac{\partial x_{v}}{\partial v}=(\rho-1) \frac{r \pi}{v} \frac{v^{\rho-1}}{v^{\rho}+D^{\rho}}-\rho v^{\rho} \frac{r \pi}{v} \frac{v^{\rho-1}}{\left(v^{\rho}+D^{\rho}\right)^{2}}=0 .
$$

Solving Eq. (3) for $v$ gives the following:

$$
v=(\rho-1)^{\frac{1}{\rho}} D
$$

Equation (4) describes the optimal size of the raiding group as an increasing function of the size of the defense force faced. Note that $v$ is undefined unless $\rho>1$, echoing the ideas described in Fig. 1. Agglomeration into a larger raiding group will only take place if the degree of decisiveness in conflict is sufficiently high. ${ }^{17}$ Plugging $v$ from (4) into (2) gives an expression for the returns earned by any particular Viking village participating in a raiding group of optimal size:

$$
x_{v}^{*}=\frac{r \pi}{D} \frac{(\rho-1)^{1-\frac{1}{\rho}}}{\rho} .
$$

\footnotetext{
16 Our analysis is thus in the spirit of Alesina and Spolaore $(1997,2005 a, b)$ in that we describe the most efficient size of a raiding (or defending) group, and suppose that over time groups will tend to their efficient size. This approach says little about the details of how alliances come into being, and how this process is influenced by the strategic concerns of potential group members, as a game-theoretic study of coalition formation would, perhaps at the expense of developing a cleaner picture of how the nature of conflict technology influences group size. For a discussion of coalition formation in contests, see Garfinkel (2004), Garfinkel and Skaperdas (2007) and Sanchez-Pages (2007).

17 If $\rho<1$, the incentives for invaders are to break up into raiding parties as small as possible.
} 
Note that Eqs. (4) and (5) suggest an interesting feature of the nature of raiding and the returns to raiding. Together, (4) and (5) imply that as the size of the defense force $D$ confronted grows, a) it becomes desirable for groups to form larger groups in raiding, while at the same time b) each member village of a raiding group receives less from raiding activities. Thus, a larger defensive force deters raiding behavior, while at the same time encouraging those groups that do engage in raiding to agglomerate into larger raiding units. One can already see how our model, in equilibrium, might allow for seemingly anomalous historical phenomena to occur simultaneously. It is plausible that a larger fraction of the Viking population may engage in peaceable activities while at the same time, those raids that do occur will be larger and more sophisticated. (Out of equilibrium dynamics, as explored in the next section, are consistent with a broader range of outcomes, including increases in both raid size, $v$, as well as raiding activity, $n_{v}$, in general.) To determine explicitly the size of the raiding population, suppose that (agricultural) production in Scandinavia is governed by a production function of the form:

$$
Q=A n_{f}^{1-\alpha} R^{\alpha}
$$

where $R$ is the common resource base used in production. Home production is subject to crowding; in accordance with this, suppose that there is free access to the means of production in Scandinavia, so each group gets its average product from land production. Using the identity $n=n_{v}+n_{f}$, we have:

$$
x_{f}=\frac{Q}{n_{f}}=A\left(\frac{R}{n-n_{v}}\right)^{\alpha^{18}} .
$$

In equilibrium returns from engaging in raiding and engaging in farming must be equal, so using (5) and (7) we have an equilibrium condition describing the split of Viking villages between raiding and farming:

$$
A\left(\frac{R}{n-n_{v}}\right)^{\alpha}=\frac{r \pi}{D} \frac{(\rho-1)^{1-\frac{1}{\rho}}}{\rho} .
$$

Solving (8) for $n_{v}$ gives the following:

$$
n_{v}=n-R\left(\frac{\rho A D}{r \pi(\rho-1)^{1-\frac{1}{\rho}}}\right)^{\frac{1}{\alpha}} .
$$

One interpretation of (9) is as a sufficient condition for the onset of raiding activity, given that the English are unprepared for raiding. For example, assume the English

\footnotetext{
18 While we have assumed that the returns to farming are governed by average product, it is possible to replace average product with marginal product. In this case, we would have a coefficient out in front of the thing. As long as the returns per village to engaging in farming are decreasing in the number of villages, results do not change.
} 
have some initial amount of defense $\underline{D}$. Upon substituting this into the above, one can see that the number of raiding villages is positive if:

$$
\frac{n}{R}>\left(\frac{\rho A \underline{D}}{r \pi(\rho-1)^{1-\frac{1}{\rho}}}\right)^{1 / \alpha}
$$

From (10) one can see that raiding is more likely to commence the greater the population of the raiding country (an increase in $n$ ), the fewer the resources or poorer the environment in Scandinavia (a fall in $R$ ), the worse the technology/productivity of land on the home front (a decrease in $A$ ), the greater the profitability of raiding (an increase in $\pi$ ), and the easier it is to conduct raids (an increase in $r$ ). It is relatively easy to endogenize any of these variables and analytically solve for the beginning of the raiding era. But because there are multiple candidates to endogenize (e.g. resource depletion $d R / d t$, prize accumulation $d \pi / d t$, or technical change, $d r / d t$ ) and the limited empirical evidence on which candidate is most relevant, we refrain from such efforts in this paper. However, we do no note that one might interpret historians" "land thirst" and "better shipping technology" arguments as resulting from an exogenous decrease in $R$ or increase in $r$. An increase in population $n$ also makes raiding more likely, which is in line with the (contested) hypothesis that overpopulation was a cause of increased raiding activity. Thus, Eq. (10) constitutes broad verification of the various explanations for the onset of Viking raids at the end of the eighth century. ${ }^{19}$

We can use Eq. (9) to solve for a critical level of defenses that would deter conflict. Upon setting $n_{v}=0$ and solving, this threshold is: $\bar{D}=n^{\alpha} r \pi(\rho-1)^{(\rho-1) / \rho}(R A)^{-1}$. If the British are able to muster defense levels equal to $D \geq \bar{D}$ then raiding becomes an unprofitable activity, and all Viking villages would opt for farming.

Let us now consider the decisions of the defending English population. They must decide how much to invest in defending resources and the group size they should agglomerate into in order to best deal with invaders. What we have in mind is a situation in which a cluster of English villages decides to combine each of their individual defensive resources (their local armies) into one large force, which is deployed to the necessary place when any village in the alliance of defensive villages is raided. Define $e$ as the size of the defending alliance, or the number of villages pooling forces.

There is an obvious possibility that group members may attempt to free-ride on the efforts of others. The problem of organizing defenses is different than the raider's problem in that members of a group have an incentive to free-ride; for example, by refusing to provide defending forces when a fellow village is attacked. There must be some sort of institution in place that "coerces" members of a defending group to participate in the collective defense of its members. ${ }^{20}$ Suppose that the total costs of managing an alliance of size $e$ can be written as $C_{e}(e), C^{\prime}>0, C^{\prime \prime}>0$. Administrative costs are borne equally among all participating villages so administrative costs

\footnotetext{
19 Condition (10) may also shed light on the reason why the British did not start raiding the Vikings-if the right-hand side of (10) is sufficiently large, organizing such raids simply does not pay.

20 Transactions costs are much less important to raiders, it can be argued, because if they do not participate as described by group rules, they can be excluded from winnings.
} 
per village are $c_{e}(e)=C_{e}(e) / e$; under the assumptions governing the shape of the cost function, $c_{e}(e)$ is also increasing in the size of the alliance. Denote the losses (assets stolen and property damaged) experienced by the typical village in the event of a successful attack as $\pi$ (also the amount seized by attackers in a successful raid) and the size of the average invading force as $G$, which is taken as given by defenders when the size of the group is determined. Finally, suppose that the typical defending group experiences $\tilde{r}$ raids. Per village, total expected costs (defense, management, and raiding) are:

$$
L_{e}=\pi \tilde{r} \frac{G^{\rho}}{G^{\rho}+(e d)^{\rho}}+c_{e}(e) .
$$

The optimal size of a defensive alliance can then be obtained by choosing $e$ to minimize (12) given $d$ (now the defense contribution per village), which we normalize to unity (again, see the appendix for a more elaborate specification with free choice of both $e$ and $d$ ). The first-order condition for is:

$$
\tilde{r} \pi \frac{\rho e^{\rho} G^{\rho}}{e\left(G^{\rho}+e^{\rho}\right)^{2}}-c_{e}^{\prime}(e)=0 .
$$

If attacks are randomly distributed among English villages, and there are $n_{v} / v$ distinct raiding groups which each carry out $r$ raids, we have $\tilde{r}=r n_{v} /\left(v n_{e}\right)$ as the average number of raids experienced by the typical English village. Above we assumed that the typical raiding force was equal to the number of villages in the group, so $G=v$. Thus, (13) can be rewritten as:

$$
c^{\prime}(e)=r \frac{n_{v}}{v n_{e}} \frac{\rho e^{\rho} v^{\rho}}{e\left(v^{\rho}+e^{\rho}\right)^{2}} .
$$

Equation (14) permits a closed-form solution only for specific functional forms. In the case that the total costs of maintaining a defensive alliance of size $e$ are given by $C(e)=c e \ln (e)$ - so that $C^{\prime}>0$ and $C^{\prime \prime}>0$ still hold—and administrative costs are borne equally by all villages, then $C(e) / e=c \ln (e)$ defines administrative costs per village, and condition (14) becomes:

$$
c=r \frac{n_{v}}{v n_{e}} \frac{\rho e^{\rho} v^{\rho}}{\left(v^{\rho}+e^{\rho}\right)^{2}}
$$

Solving (15) for $e$ gives:

$$
e=v\left(\frac{\sqrt{\rho \pi r n_{v}\left(\rho \pi r n_{v}-4 c v n_{e}\right)}+\rho \pi r n_{v}-2 c v n_{e}}{2 c v n_{e}}\right)^{\frac{1}{\rho}}
$$

Equation (16) describes a reaction function for English villages as a function of both the size of the raiding population and the size of the typical raiding group. Figure 2 provides a graph of the reaction function, showing the optimal size of a 


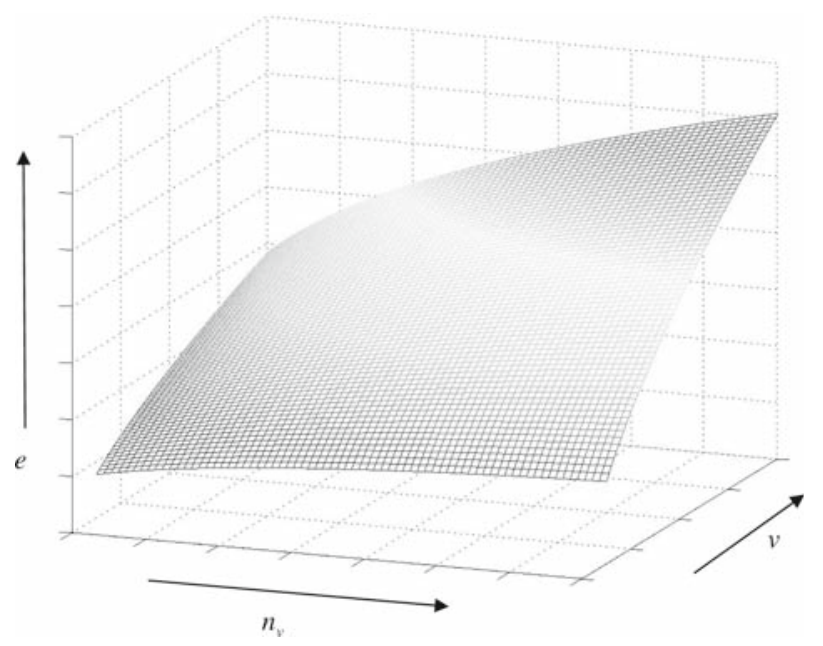

Fig. 2 The reaction function of the defending population

defensive alliance as a function of $n_{v}$ and $v$. The optimal size of a defending alliance is increasing in both the number of raids and the number of Viking villages involved in the attacks.

We shall see that using (4), (9), and (16), we can describe a simple dynamic model of the process of agglomeration in conflict. Before doing so, it is worthwhile to consider what the simultaneous solution of (4), (9), and (16) tells us about the scale of defense, the scale of raiding, and overall participation in raiding activities. A closed-form solution can be obtained for the special case when $\alpha=1$, or when the opportunity cost of raiding effort is invariant with respect to the number of Vikings in the peaceful occupation. We then find that:

$$
e^{*}=\frac{\pi r n(\rho-1)^{1-\frac{1}{\rho}}}{\rho\left(c n_{e}+R A\right)} ; \quad v^{*}=\frac{\pi r n(\rho-1)}{\rho\left(c n_{e}+R A\right)}, \quad n_{v}=\frac{n c n_{e}}{c n_{e}+R A} .
$$

A first observation from (17) is the way in which the costs of agglomeration for defenders (which might be taken to represent the talents of a particular king) influence the equilibrium levels of agglomeration in the defending country, but also simultaneously determine the size of raiding groups. As administrative costs increase (i.e., a larger value for the parameter $c$ ), the equilibrium size of defending alliances falls, while the number of Viking villages participating in raiding rises and the size of the typical raiding group falls.

Equation (17) also indicates that population increases in the invading country also cause increases in the equilibrium organization of both defending and raiding groups. The logic is that defenders must become more organized to deal with the increased threat of raiding; the raiding population then faces an incentive to increase the size of their armies to overcome the more concerted defenses. Finally, one can also see from (17) that equilibrium agglomeration of raiders and defenders increases as the 
winnings to successful raids occur (an increase in $\pi$ ). An interpretation of this result is that increased commercial activity in Northern Europe increased incentives for raiding, which in turn eventually resulted in larger English political units and larger Viking armies.

\section{Adding dynamics}

The solutions described in Eq. (17) summarize the equilibrium of the Nash game between invaders and their victims. An equally interesting issue concerns the development trajectories towards the equilibrium - does one obtain with this model temporal patterns that fit stylized facts well so that, over time, the size of Viking raiding groups and English defensive alliances grow larger?

Putting the model above in a dynamic context requires distinction between three different state variables: Viking group size $(v)$, Defenders' group size $(e)$ and the number of Viking villages engaged in raiding $\left(n_{v}\right) .{ }^{21}$ While it is possible to track such a model over time, it is cumbersome to do so and it is hard to capture the dynamics in a simple phase plane. For this reason, and because the qualitative results are unaffected, we simplify the model by assuming that the Vikings are able to instantaneously cluster into invasive groups of the optimal size. Hence, $v=v^{*}(e)$, as derived in (4), holds always. Note that this does not mean that group size is stable: it varies over time as the size of the defensive group changes (also note that the overall number of groups varies, as discussed below).

Consider first the clustering process of the Vikings. As described in Sect. 2, this clustering process involved the transition from decentralized decision-making towards substantial kingdoms. Arguably, such kings would have a say in the allocation of resources across activities (farming and raiding) and the division of farming harvests and raiding spoils across social groups in society. To retain a tractable model we refrain from explicitly modeling this transition of authority (but see Baker et al. 2010). Instead, we take an analytical shortcut and assume that both decentralized and centralized decision-makers are responsive to profit differentials between agriculture and raiding, so that resources are switched from less to more profitable occupations. ${ }^{22}$ It is reasonable to assume that such responses only occur with a time lag. There may be many reasons why switching is not immediate, some rooted in psychology and others caused by matters like incomplete information, transaction and/or adjustment costs, and so on. Given the choice of the optimal alliance size, the dynamics of the labor

\footnotetext{
21 Note that the number of "victim villages" $-\mathrm{n}_{\mathrm{e}}$ - is exogenous and fixed: the British cannot choose to opt out of the game- although they certainly would have liked to.

22 While the outcome in terms of the allocation of resources across farming and raiding in response to profit differentials may be similar for decentralized and centralized models, a case can be made that distributing the raiding group's spoils is easier in the context of a king (individual villages have to solve a coordination problem). We refrain from analyzing the stability of the coalition, precisely because the historical evidence suggests the contemporaneous emergence of Scandinavian kingdoms attenuated concerns about coordination. As alluded to above in footnote 15, an explicit measure of coordination costs could be included in the model, but this would not alter the model's main results.
} 
allocation choice may be described by the following ad hoc specification:

$$
\frac{d n_{v}}{d t}=\phi\left[x_{v}-x_{f}\right]=\phi\left[\frac{r \pi}{e} \frac{(\rho-1)^{1-\frac{1}{\rho}}}{\rho}-A\left(\frac{R}{n-n_{v}}\right)^{\alpha}\right]
$$

where $\phi$ is an adjustment or sluggishness parameter, measuring the speed with which "switching" occurs in response to profit differentials, which is determined by adjustment costs, the speed of information flows, and so on. Equation (18) is a variant of the well-known replicator equation that is commonly used in evolutionary game theory (it is slightly different from the conventional specification as the decision-makers compare the payoffs from raiding and farming, rather than the returns from either specific activity to the population average outcome, but this implies no loss of generality). ${ }^{23}$ In equilibrium, returns from engaging in raiding and engaging in farming must be equal, and Eq. (9) simply provides the $d n_{v} / d t=0$ isocline.

Similarly, we may expect that defenders will cluster in defensive alliances if this is profitable for them, and that the size of these alliances will continue to grow as long as having additional members increases the payoff of all members. Again, the pace at which this happens is arbitrary, and we may specify the dynamics as:

$$
\frac{d e}{d t}=-\xi\left[\frac{d L_{e}}{d e}\right]
$$

where $\xi$ is a parameter capturing the speed of adjustment. In equilibrium, the marginal gain of having an additional member is zero, and using (17), the $d e / d t=0$ isocline is simply:

$$
e=\frac{(\rho-1) \pi r}{\rho c n_{e}(\rho-1)^{1 / \rho}} n_{v}=\Omega n_{v} .
$$

Figure 3 combines the isoclines (18) and (20) in a phase plane, and also displays how the size of the typical Viking raiding group develops (the lower quadrant). From Fig. 3, three results stand out. Starting from a 'decentralized beginning' without significant cooperation between like-minded villages - i.e. close to the origin in the southwest part of the phase plane-we see that $n_{v}, v$ and $e$ all grow over time. The number of Viking villages engaging in raiding increases because raiding is a relatively profitable occupation, and these extra efforts are 'matched' to a certain extent by the English who cluster in large defensive groups in response to the raiding activity. In turn, the

\footnotetext{
${ }^{23}$ Replicator dynamics have the disadvantage in that they imply decision-makers are myopic and unsophisticated, in that they suggest agents do not anticipate the optimizing behavior of other agents. However, replicator dynamics are also a portmanteau means of capturing what can be complex interactions between agents in a simple fashion. The gradual adoption of more favorable courses of action implied by replicator dynamics might be thought of as the result of a gradual learning process, where villages learn through observation of the payoffs and actions of neighboring villages. Replicator dynamics may also be thought of as the result of competition among raiding villages, so that those villages adopting higher-payoff strategies survive and multiply. See Mailath (1992) and the references therein for a more thorough description of assumptions underlying replicator dynamics.
} 
Fig. 3 Dynamics of viking raiding effort and alliance size: one possible trajectory

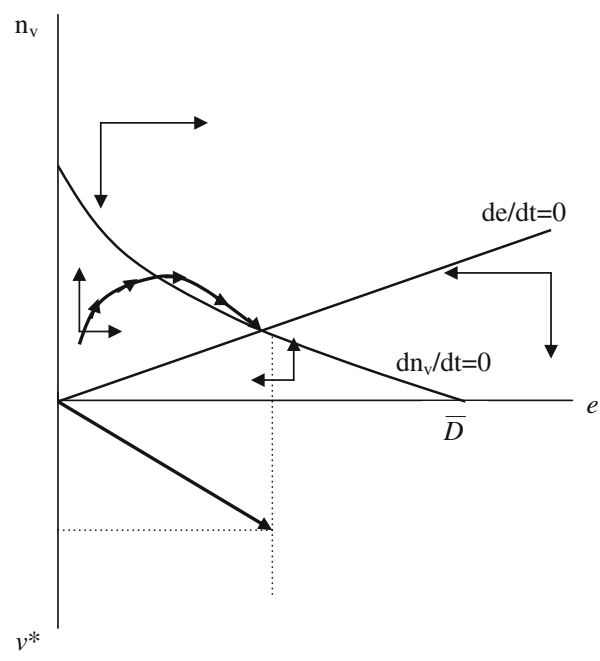

Vikings also cluster in larger groups, providing a further impetus for English villages to cluster into larger defensive alliances.

The number of Viking villages engaged in raiding need not monotonically increase over time. Figure 3 provides one such non-monotonous trajectory: while alliance size on both sides of the battle field continues to increase, profits from raiding fall, so that some Viking villages find it in their interests to return to farming. Alternative outcomes are also feasible. For different initial values or parameters the system displays a monotonic approach or cyclical behavior. In case of "cycles" the size of Viking raiding and English defensive alliances goes up and down - suggesting an ebb-and-tide pattern of the complexity of conflict. A rich set of results are obtainable, and it is unfortunate that the historical record is not detailed enough to select the most appropriate outcome. That having been said, we believe that both the node and focus outcome may be consistent with what is known about this era. ${ }^{24}$

In concluding this section, we can use the model to say something about the final phase of the Viking era-the transition from raiding to other activities such as trade. It is evident that effort will shift from raiding to farming if (due to some exogenous process such as the conversion to Christianity or some endogenous process as the discouraging effect of continued raiding on the British incentive to accumulate wealth) the benefits from raiding, as represented by the parameter $\pi$, become smaller. This rotates the $d n_{v} / d t=0$ isocline clockwise. Effort will be re-allocated away from raiding if English institutions develop so that coordination costs $c$ are reduced (rotating the $d e / d t=0$ isocline clockwise). For sufficiently large changes in $\pi$ and $c$, raiding ceases. On a more speculative note, it could be argued that after the stage was set for agglomeration into sufficiently large "states," the perspective of the decision makers changed. That is, the affairs and interests of the nation-state, rather than the benefits

\footnotetext{
24 The empirical facts are rather obscure on this matter. For example, it is hard to determine whether more or less Viking villages got involved in the raids over time as the Viking era drew to a close.
} 
of a bunch of independent armies, took primacy. This could induce greater emphasis on things such as mutually beneficial trade and statecraft. ${ }^{25}$

\section{Discussion and conclusions}

The main insight of the paper is that the nature of the conflict technology can set into motion a process of competitive agglomeration. The process we have modeled suggests a gradual process of clustering of force, and of evolving from decentralized decision-making to centralized authorities. For sure, the latter interpretation is not explicit in the model, which is rather agnostic about the nature of how coordination processes are solved. One straightforward conjecture, however, is that the era of the Vikings provided an impetus to the for the process of state formation in Europe, both for raiders and defenders. If so, interactions between raiding and defending populations, and the degree of decisiveness in conflict, played a role in forging the nature of modern Europe by setting in motion forces that led to agglomeration of fighting forces into ever larger nation-states. It is unlikely that Alfred could have conducted his centralization plan without the interventions of the Vikings, and the gradual escalation in the size and nature of conflict during the early Viking age certainly aided in setting the stage for the achievements of Knut (Canute the Great), and William the Conqueror.

Some historical research supports our conjecture that Viking raids were are the cradle of European state formation. Kirby (1991) refers to the historical tradition of "heptarchy" of English Kingdoms existing prior to the Viking age, but argues that in fact this was almost certainly a gross overstatement of the degree of centralization in pre-Viking England. However, centralization of authority soon followed. Sawyer (1997) writes "by 870 there had been profound changes in Franka and in England." Under Alfred the Great in the late ninth century a centralized system of forts and coastal defenses (the burghal system) were constructed. The fortresses overlooked most of the landscape of the West Saxon kingdom, serving both as fortified points for defense and as launching points for garrisoned defensive armies. The system also aided in consolidating centralized rule. These centralized controls and institutions were extended and further developed under Edward and Aethelstan, and a variety of innovations appear in tenth century English law. The trend towards larger political units was reflected in the newly emergent, broader definition of kingship (see Abels 1988a). Indeed, a sense of common identity had slowly emerged among the English in the face of the Viking raids, most dramatically reflected in the law codes of Wulfstan II, which declared that the English should follow one faith, under the leadership of one king (Keynes 1997).

As in England, Scandinavians societies transformed as Viking raids evolved into larger-scale affairs. Sawyer (1994) discusses the possibility that there were fewer kingdoms in Scandinavia at the end of the first millennium than there had been 200 years earlier when raiding activity began, noting further that while early Viking activity was largely the work of raiders, “....in the late tenth and eleventh centuries Scandinavian

\footnotetext{
25 Alternatively, one could introduce a third activity (such as "trading") into the model from the outset. While perhaps not competitive at early stages, trading may become more attractive over time as seafaring technologies improved through some learning-by-doing process (lowering transaction costs of this activity, and allowing it to eventually dominate the others).
} 
Kings led Viking raids..." (Sawyer 1994, 144-145). By the ninth century Viking invasions more closely resembled exercises in empire building than raiding, and Norway and Denmark had evolved into relatively unified kingdoms, albeit in fits and starts. The Danish kings Sven Forkbeard and Canute (Knut) the Great succeeded in building large, if short-lived, kingdoms. The process which began with small-scale raids had gone a long way in creating incentives for Europeans to organize themselves into larger countries, and therefore exercised a profound impact on the future shape of Europe. Hence the conjecture that the Viking era played an important role in the process of creating central governments, enabling societies to reap the benefits of coordination and introducing a plethora of issues related to political economy, institutions and governance.

Theorizing about the notion that war and defense are linked to the size of nations is not new. Both social contract theories and predatory theories of the emergence of hierarchy and governments have been proposed (Olson 1993; Grossman 2002). Alesina and Spolaore (2005a,b), for example, argue that the size of countries is determined by a need to balance "heterogeneity costs" (associated with jurisdictional expansion) and scale economies that come with the provision of public goods provision such as defense effort. They show that the number of countries should increase in response to a reduction in the probability of conflict but that, in turn, the increase in number of independent nations may result in a greater number of conflicts. ${ }^{26}$ We have shown that fixed costs of public good provision are not necessary to achieve consolidation in larger political units. Instead, we look at the conflict technology, which introduces a competitive aspect to agglomeration. It links the inherently static literature on optimal nation size to the dynamic literature on arms races.

Of course, our model of this process is a highly stylized and incomplete representation of reality. A number of extensions are feasible. For example, it would be interesting to include population dynamics, in particular because changes in the population affect potential strength on the battlefield. Alternatively, explicitly accounting for the wealth generation process of the victims may be a useful avenue of future research-accounting for the fact that increasing defensive efforts reduces the speed with which assets may be accumulated, and accounting for the fact that the time lag between successive attacks affects the available loot. Third, one could consider the challenges facing multiple populations (such as Franks and English) confronted by a common threat might be interesting, as well as more explicitly considering game theoretic aspects of the agglomeration problem. Regardless, the main notions outlined in these pages propose a direct connection between the distant horrors of the Viking era and modern fields of research related to managing nation states.

Open Access This article is distributed under the terms of the Creative Commons Attribution Noncommercial License which permits any noncommercial use, distribution, and reproduction in any medium, provided the original author(s) and source are credited.

26 They also demonstrate that this implies that the peace dividend may be smaller than perhaps anticipated. 


\section{Appendix}

\section{A. Varying invasive effort levels}

We first describe how varying invasive effort levels alter the basic nature of the problem. The main result of interest is that allowing invading groups to vary their level of activity alongside the agglomeration decision does not qualitatively change the participation function and the returns from engaging in conflict, so long as one includes some degree of increasing costs for each group to raiding. The logic behind this result is that no individual raiding group would wish to agglomerate into a larger group if it could increase its size without disproportionately increasing its costs. Along these lines, consider the modified returns-to-raiding function after (2);

$$
x_{v}=\frac{r \pi}{v} \frac{(g v)^{\rho}}{(g v)^{\rho}+D^{\rho}}-c(g) .
$$

To take a specific example, suppose that $c(g)=c_{g} g^{2}$. Differentiating (A.1) with respect to both $g$ and $v$ (which implies that invasive effort can be chosen so as to maximize the returns from raiding of the average group member), and solving the resulting first-order conditions for $g$ and $v$ gives the solutions:

$$
g=\frac{1}{2} \frac{r \pi(\rho-1)^{1-\frac{1}{\rho}}}{c \rho D} ; \quad v=2 \rho \frac{D^{2} c(\rho-1)^{\frac{2}{\rho}-1}}{r \pi}
$$

The solutions in (A.2) imply that the overall size of the raiding group, $G=g v$, can be readily shown to be the same as that given in Eq. (4). Substituting the solutions in (A.2) back into (A.1) gives:

$$
x_{v}=\frac{1}{4} \frac{r^{2} \pi^{2}(\rho-1)^{2\left(1-\frac{1}{\rho}\right)}}{\rho^{2} c D^{2}}
$$

The expression in (A.3) has the same qualitative properties as the return function used in Eq. (9) to derive equilibrium raiding participation; thus, the qualitative characteristics are not altered by the simplifying assumption that raiding effort is fixed. It is, however, of some interest to note that closed form solutions for reaction functions are still obtainable in this case.

\section{B. Varying levels of defensive effort}

Consider now a case in which we allow defending groups to invest in variable amounts of defense, for a given amount of raids. This gives a total raiding cost function of the form:

$$
L_{e}=\pi \tilde{r} \frac{G^{\rho}}{G^{\rho}+(e d)^{\rho}}+c_{e}(e)+c_{d}(d)
$$


Which means that we have the following first-order conditions:

$$
\begin{aligned}
& \frac{\partial L_{e}}{\partial e}=-\pi \tilde{r} \rho \frac{(e d)^{\rho}}{e} \frac{G^{\rho}}{\left[G^{\rho}+(e d)^{\rho}\right]^{2}}+c_{e}^{\prime}(e)=0, \\
& \frac{\partial L_{e}}{\partial d}=-\pi \tilde{r} \rho \frac{(e d)^{\rho}}{d} \frac{G^{\rho}}{\left[G^{\rho}+(e d)^{\rho}\right]^{2}}+c_{d}^{\prime}(d)=0 .
\end{aligned}
$$

Together, these two conditions imply that the following must hold:

$$
c_{d}^{\prime}(d) d=e c_{e}^{\prime}(e)
$$

Note that in the case we explored in the text, where $c_{e}(e)=c_{e} \ln (e)$, this would imply that $c_{d}^{\prime}(d) d=c_{e}$, so that $d$ would be set at a constant level, regardless of the level of agglomeration across groups. In a more general case, results still would not substantially alter our approach. For example, if we supposed that $c_{d}(d)=c_{d} d^{\lambda_{d}} \lambda_{d}^{-1}$, and $c_{e}(e)=c_{e} e^{\lambda_{d}} \lambda_{e}^{-1},(\mathrm{~A} .7)$ implies that $c_{e} e^{\lambda_{d}}=c_{d} d^{\lambda_{d}}$, or $d=e^{\lambda_{e} / \lambda_{d}}\left(c_{e} / c_{d}\right)^{1 / \lambda_{d}}$. Plugging this into (A.5) gives:

$$
\frac{\partial L_{e}}{\partial e}=-\pi \tilde{r} \rho \frac{\left(\left(c_{e} / c_{d}\right) e^{1+\lambda_{e} / \lambda_{d}}\right)^{\rho}}{e} \frac{G^{\rho}}{\left[G^{\rho}+\left(\left(c_{e} / c_{d}\right) e^{1+\lambda_{e} / \lambda_{d}}\right)^{\rho}\right]^{2}}+c_{e}^{\prime}(e)=0
$$

Expression (A.8) is a more complex version of (13), though it has the same basic properties.

\section{Larger groups can conduct more raids}

In the historical record, it appears that some of the larger Viking armies stayed together for substantial amounts of time; therefore, a logical extension is to consider a situation in which a larger army can stay together for longer periods of time and conduct more raids over this period of time. This would also allow the size of the prize to expand with the number of groups. Along these lines, one might replace expression (2) with:

$$
x_{v}=\frac{r v^{\gamma} \pi}{v} \frac{v^{\rho}}{v^{\rho}+D^{\rho}}
$$

In expression (A.9), the term $r v^{\gamma}, 0 \leq \gamma<1$ describes how the number of raids expands as group size expands, where now $r$ denotes the number of raids that can be conducted by a raiding group composed of a single village. The optimal raiding group size is given by:

$$
v^{*}=\left(\frac{\gamma+\rho-1}{1-\gamma}\right)^{\frac{1}{\rho}} D
$$


Plugging this back into (A.9) gives:

$$
x_{v}^{*}=\left(\frac{\gamma+\rho-1}{1-\gamma}\right)^{\frac{\gamma+\rho-1}{\rho}} \frac{(1-\gamma)}{\rho} \frac{r \pi}{D^{1-\gamma}}
$$

The raiding returns described in (A.11) have the same basic functional form as the returns described in (A.5), except for being a bit less responsive to changes in $D$.

\section{References}

Abels RP (1988a) Alfred the great: war, kinship, and culture in Anglo-Saxon England. Longman, London Abels RP (1988b) Lordship and military obligation in Anglo-Saxon England. University of California Press, Berkeley

Alesina A, Spolaore E (1997) On the number and size of nations. Q J Econ 112:1027-1056

Alesina A, Spolaore E (2005a) War, peace, and the size of nations. J Pub Econ 89:1333-1354

Alesina A, Spolaore E (2005b) Conflict, defense spending and the number of nations. Eur Econ Rev (in press)

Baker MJ (2003) An equilibrium conflict model of land tenure in Hunter-Gatherer societies. J Polit Econ 111:124-173

Baker MJ, Bulte EH, Weisdorf J (2010) The origins of governments: from anarchy to hierarchy. J Inst Econ (in press)

Bolton P, Roland G (1997) The break-up of nations: a political economy analysis. Q J Econ 112:1057-1090

Buchanan J (1975) The limits of liberty: between anarchy and leviathan. University of Chicago Press, Chicago

Craughwell TJ (2008) How the barbarian invasions shaped the modern world. Fair Winds Press, Beverly

Friedman D (1997) A theory of the shape and size of nations. J Polit Econ 85:59-77

Garfinkel M (2004) Stable alliance formation in distributional conflict. Eur J Polit Econ 20:829-852

Garfinkel M, Skaperdas S (2007) Economics of conflict: an overview. In: Sandler T, Hartley K, Handbook of defense economics vol. 2 (Chap. 22). North Holland, Amsterdam

Gettleman J (2008a) Somali pirates capture tanks and unwanted global notice. The New York Times, p A1

Gettleman J (2008b) Pirates tell their side: they want only money. The New York Times, p A6

Gettleman J (2008c) Pirates in skiffs still outmaneuvering warships off Somalia. The New York Times, p A6

Gettleman J (2009) Eluding an armada of patrol vessels, Somali pirates seize five ships in 48 hours. The New York Times, p A8

Gonzalez FM (2005) Insecure property and technological backwardness. Econ J 115:703-721

Griffith P (1995) The viking art of war. Greenhill Books, London

Grossman HI (1991) A general equilibrium model of insurrections. Am Econ Rev 81:912-921

Grossman HI (2002) Make us a king: anarchy, predation, and the state. Eur J Polit Econ 18:31-46

Grossman HI, Kim M (1995) Swords or plowshares? a theory of the security o cliams to property. J Polit Econ 103:275-288

Grossman HI, Mendoza J (2003) Scarcity and appropriative competition. Eur J Polit Econ 19:747-758

Hirshleifer J (1991) The paradox of power. Econ Polit 3:177-200

Hirshleifer J (1995) Anarchy and its breakdown. J Polit Econ 103:15-40

Hirshleifer J (2000) The macrotechnology of conflict. J Conflict Resolut 44:773-792

Keynes S (1997) The vikings in England c. 790-1016. In: Sawyer P (ed) The Oxford history of the vikings, pp 48-82

Kirby DP (1991) The earliest English kings. Routledge, London

Leeson PT (2006) Efficient anarchy. Pub Choice 130:41-53

Leeson PT (2007) Better off stateless: Somalia before and after government collapse. J Comp Econ 35:689_ 710

Mailath GJ (1992) Introduction: symposium on evolutionary game theory. J Econ Theory 57:259-277

Maxwell JW, Reuveny R (2005) Continuing conflict. J Econ Behav Organ 58:30-52 
McGuire M, Olson M Jr (1996) The economics of autocracy and majority rule: the invisible hand and the use of force. J Econ Lit 34:72-96

Mehlum H, Moene K (2006) Fighting against the Odds. Econ Gov 7:75-87

Neary H (1997) A comparison of rent seeking models and economic models of conflict. Pub Choice 93:373388

New York Times (2005) World briefing Africa: Somalia: pirates Attack more ships, pp A6

Olson M (1993) Dictatorship, democracy, and development. Am Polit Sci Rev 87:567-576

Olson M (2000) Power and prosperity. Basic books, New York

Poertner R (1971) The vikings (translated by S. Wilkins). St. Martin's Press, New York,

Roberts JM (1993) History of the world. Oxford University Press, New York

Sanchez-Pages S (2007) Endogenous coalition formation in contests. Rev Econ Des 11:139-163

Sandler T, Hartley K (1995) The economics of defense. Cambridge University Press, Cambridge

Sawyer PH (1994) Kings and vikings: Scandinavia and Europe AD 700-1100. Barnes and Noble Books, New York

Sawyer PH (1997) The age of the vikings. In: Sawyer PH (ed) The Oxford illustrated history of the vikings. Oxford University Press, Oxford pp 1-18

Schelling TC (1960) The strategy of conflict. Harvard University Press, Cambridge

Skaperdas S (1992) Cooperation, conflict and power in the absence of property rights. Am Econ Rev 82:720-739

Worth RF (2008) Pirates seize Saudi tanker off Kenya: ship called the largest ever hijacked. The New York Times, p A6 